Int. J. Electrochem. Sci., 14 (2019) 3336 - 3349

International Journal of

ELECTROCHEMICAL

SCIENCE

$\underline{\text { WWW.electrochemsci.org }}$

\title{
Coiled Spring-Like Hard Carbon as an Anode Material for Lithium-ion Batteries
}

\author{
Zhonghua Lu, Zeyin Guo, Xiaoxia Ren, Shou-Dong Xu* \\ College of Chemistry and Chemical Engineering, Taiyuan University of Technology, Taiyuan, \\ 030024, People's Republic of China \\ *E-mail: xushoudong@tyut.edu.cn
}

doi: $10.20964 / 2019.04 .56$

Received: 2 January 2019 / Accepted: 18 February 2019 / Published: 10 March 2019

Carbon micro-coils (CMCs) with a coiled spring-like morphology and hard carbon structure were prepared using metal $\mathrm{Ni}$ powder as a catalyst by chemical vapor deposition method at $750{ }^{\circ} \mathrm{C}$ in a mixed gas atmosphere $\left(\mathrm{N}_{2}: \mathrm{H}_{2}: \mathrm{C}_{2} \mathrm{H}_{2}=1: 3: 1\right)$. The obtained CMCs have a screw diameter of approximately 10 $\mu \mathrm{m}$ and a modest surface area of $61.2 \mathrm{~m}^{2} \mathrm{~g}^{-1}$ with a total pore volume of $0.076 \mathrm{~cm}^{3} \mathrm{~g}^{-1}$. When used as an anode material in lithium-ion batteries, CMCs electrodes exhibit excellent electrochemical performances. In particular, a comparable good cycling stability with no obvious capacity loss, preserving almost over $99.0 \%$ of capacity retention ratio can be achieved at $100 \mathrm{~mA} \mathrm{~g}^{-1}$ after 200 cycles. A lithium storage mechanism for the CMCs has been proposed based on the quantity of the mesopores, which can be applied to explain the irreversible capacity of the CMCs during the first cycle. Electrochemical impedance spectroscopy results show that the CMC electrode has small values for both the electrolytic resistance and combined resistances including the contact resistance and passivation film resistance. This study illustrates the great promise of CMCs and other hard carbon materials with unique morphologies for application in energy storage and conversion systems such as lithium-ion batteries, sodium-ion batteries and supercapacitors.

Keywords: Lithium-ion battery, Carbon micro-coils, Lithium storage mechanism, Electrochemical impedance spectra, Anode

\section{FULL TEXT}

(C) 2019 The Authors. Published by ESG (www.electrochemsci.org). This article is an open access article distributed under the terms and conditions of the Creative Commons Attribution license (http://creativecommons.org/licenses/by/4.0/). 